\title{
Letter from the Editor-in-Chief: Scientists behaving badly
}

\section{Lorraine Eden}

Journal of International Business Studies (2010) 41, 56I-566. doi: I 0. I057/jibs.20 I 0.9

\section{OVERVIEW OF 41.4}

There are 10 articles in this issue of JIBS, four of which were originally submitted to the previous editorial team and subsequently transferred to my watch. The remaining articles were wholly handled by the current editors. Many of the articles cluster around the general theme of globalization and global strategies of multinationals.

The issue begins with "An evolutionary approach to understanding international business activity: The co-evolution of MNEs and the institutional environment" by Cantwell, Dunning and Lundan. Two articles on technology and innovation follow: "International technology licensing: Monopoly rents, transaction costs and exclusive rights" by Aulakh, Jiang and Pan, and "An international multilevel analysis of product innovation" by Lederman. Global marketing strategies in the context of pressures for localization are examined in Shi, White, Zou and Cavusgil in "Global account management strategies: Drivers and outcomes" and Funk, Arthurs, Treviño and Joireman in "Consumer animosity in the global value chain: The effect of international production shifts on willingness to purchase hybrid products". Three international human resource management articles are next: Ralston, Lee, Perrewé, Van Deusen, Vollmer, Maignan, Tang, Wan and Rossi, "A multi-society examination of the impact of psychological resources on stressor-strain relationships"; Du and Choi, "Pay for performance in emerging markets: Insights from China"; and Stahl, Maznevski, Voigt and Jonsen, "Unraveling the effects of cultural diversity in teams: A meta-analysis of research on multicultural work groups". The issue concludes with two pieces from institutional and finance perspectives: Haxhi and van Ees, "Explaining diversity in the worldwide diffusion of codes of good governance", and Cumming and Walz, "Private equity returns and disclosure around the world". The issue offers a rich menu of contributions to IB research.

Rather than review the key insights of each of these papers, given the limited number of journal issues that remain within my editorial responsibility, I would like to use this letter to speak to the JIBS community of scholars about a subject that is "near and dear" to the vision my editors and I have had for the journal during our tenure: we have seen as one of our core missions the instillation of a strong Code of Ethics that guides the values and practices of JIBS authors, reviewers and editors. 


\section{SCIENTISTS BEHAVING BADLY}

The Wall Street Journal recently published a column, "New episodes of scientists behaving badly" (Felten, 2010), in which the author provides several recent examples of authors, editors and reviewers manipulating scientific journals: articles retracted after discovery of "irresponsible and dishonest" research that involved fabrication of scientific data, examples of corrupt peer review practices designed to sabotage academic competitors, and other misadventures. Things are much quieter on the "home front" at JIBS. At least to my knowledge, we have had no cases of authors fabricating data or reviewers sabotaging competitors. However, even at JIBS, we do have cases of scientists behaving badly.

\section{The JIBS Code of Ethics}

When my editorial team and I began running JIBS in July 2007, one of the earliest policy documents we wrote was the JIBS Code of Ethics (see http:// www.palgrave-journals.com/jibs/jibs_ethics_code .html). Patterned after ethics codes adopted by the science and medical journals and organized into three sections (Authors, Reviewers and Editors), the code outlined the norms and practices that the JIBS Editors intended to follow during the reviewing process (see Box 1). Every author who submitted a manuscript to JIBS, for example, was asked to confirm that he/she had read and followed the JIBS Code of Ethics. It has been a point of pride for JIBS that our Code of Ethics, as far as we know, was the first ethics code written specifically for and adopted by any scholarly business journal.

Our reasoning behind creating the JIBS Code of Ethics was that journal ethics is a public good. We all benefit when authors keep high standards for themselves in their journal submissions. Reviewers can be confident that manuscripts are wholly original and have not appeared or will appear elsewhere, and that the novelty in the manuscript has been accurately portrayed by the author. Editors do not have to worry about originality or "slicing and dicing". The costs of search, monitoring and enforcement are reduced for the editorial team. Authors do not suffer the loss of reputation (and other possible impacts such as denial of promotion or tenure) that can occur if they engage in major ethical violations that become public knowledge. A code of ethics thus can act as an ex ante dispute resolution mechanism, whereby authors are encouraged to behave ethically, reducing the number of ethical violations that need to be handled ex post by
Box 1 Preamble to the JIBS Code of Ethics

The Journal of International Business Studies (IIBS) aspires to
select and publish, through peer review, the highest quality
research in international business. In order to achieve this
goal, the entire peer review and publication process should
be thorough, objective and fair. Journal reputation depends
heavily on the trust by all stakeholders in the fairness of the
peer review and publication process. A formal code of ethics,
outlining guidelines for good behavior and proposing
solutions to ethical dilemmas facing Authors, Editors and
Reviewers, can build stakeholder trust and improve journal
reputation. With this goal in mind, the JIBS Code of Ethics is
designed to be a comprehensive policy for peer review and
publication ethics in the Journal of International Business
Studies. The Code describes JIBS's policies for ensuring the
ethical treatment of all participants in the peer review and
publication process. JIBS Authors, Editors and Reviewers are
encouraged to study these guidelines and address any
questions or concerns to the JIBS Editor-in-Chief, Lorraine
Eden, at editor-in-chief@jibs.net. These guidelines apply to
manuscripts submitted to JIBS starting 1 July 2007, and may
be revised at any time by the Editor-in-Chief.
Source: http://www.palgrave-journals.com/jibs/
jibs_ethics_code.html.

the journal editors, and reducing costs throughout the editorial review process. The real benefit is the public good of providing researchers with confidence in the reliability of the reviewing process, as illustrated in this quote from the fifth edition of the CBE Style Manual reproduced in Wilson (2002: 159):

\begin{abstract}
Scientists build their concepts and theories with individual bricks of scientifically ascertained facts, found by themselves and their predecessors. Scientists can proceed with confidence only if they can assume that the previously reported facts on which their work is based are indeed correct. Thus all scientists have an unwritten contract with their contemporaries and those whose work will follow to provide observations honestly obtained, recorded, and published. This ethic is no more than science's application of the ancient Golden Rule: "Do unto others as you would have them do unto you." It is an ethic that should govern everyone in the community of scientists when they serve as authors, editors, or manuscript referees.
\end{abstract}

\section{Examples}

While the JIBS Code of Ethics formalized these norms into practical "dos and don'ts", it was written without "teeth" in that the code did not outline what the punishments would be for violations. Each time an ethical dilemma occurred (for example, a case of plagiarism) the JIBS Editors dealt with the problem on a confidential, case-by-case basis. 
Unfortunately, for whatever reasons, several ethical violations have come to light over the past six to eight months, typically through the conscientious whistle-blowing activities of our reviewers. As a result, the JIBS Editors began to think about ways to strengthen and better disseminate the code. Other journals and professional associations were clearly engaged in similar discussions (Kacmar, 2009; Schminke, 2009).

Perhaps some case examples would be helpful. One ethical problem that we have seen at JIBS recently is redundancy (self-plagiarism). In this case, an author submits a manuscript to JIBS where multiple paragraphs in the paper are identical to those in an existing published paper or a paper under review at another journal, written by the same author. In such cases, the JIBS Editors may differentiate between major and minor redundancy depending on the amount and content of the selfplagiarized material. For example, a single duplicate paragraph describing the research methods would probably be seen as minor redundancy and the authors asked to rephrase the duplicate sentences. However, multiple paragraphs would be considered major redundancy, leading to rejection of the manuscript. ${ }^{1}$

A second ethical problem that JIBS has faced is failure to cross-reference. In this situation, an author cuts up a research project into multiple small papers and does not clearly identify in each paper what exactly is new relative to other manuscripts by the same author. By failing to cross-reference the other manuscripts, the author misleads the reviewers and editor into believing that each manuscript is much more novel than it really is. In such cases, the author has not provided sufficient information for the editor and reviewers to make an informed judgment on a submission's contribution.

I provide three specific examples of redundancy and/or failure to cross-reference at JIBS. First, a manuscript was under review at JIBS when a similar manuscript by the same author appeared in print in another journal. Comparison of the two manuscripts showed that the theory, primary data set and some hypotheses were identical in the two papers, so the originality of the JIBS submission was significantly reduced. Second, a manuscript was under review at JIBS and a similar manuscript by the same author was under review at another journal. An individual who happened to be asked to review both submissions identified significant overlap in the primary data set, hypotheses and tables. Third, an author made minor revisions and resubmitted to JIBS an article that had been previously rejected after review at JIBS, requesting a different Area Editor and not informing the JIBS Office of the earlier rejection. The duplicate paper was discovered by a reviewer who had been invited to review the current and the earlier manuscript. (See Schminke (2009) for a similar example.)

In all three cases, the author withheld key information that would have led to rejection of the manuscript had that information been provided since all three papers violated the originality norms in the JIBS Code of Ethics. As a result, each manuscript looked as if it were making a greater contribution to the literature than it really was, once compared to the second manuscript. ${ }^{2}$ As journal editors rely primarily or wholly on authors to disclose relevant information and are generally not in a position to verify authors' statements, such withholding damages the peer review process since the probability of detection depends in many cases on serendipity or "sheer accident" (Schminke, 2009: 587-588).

A third ethical problem we have seen at JIBS is authors ignoring conflicts of interest (COIs), that is, "the abuse - actual, apparent or potential - of the trust that individuals have in professionals". A COI is created when "financial or personal considerations have the potential to compromise or bias one's professional judgment and objectivity" (Responsible Conduct of Research, 2010). A COI can be real, apparent (that is, where a reasonable person believes that the professional's judgment is likely to be compromised) or potential (where a situation may develop into an actual COI).

COIs can be decomposed into two categories, financial and intangible, with the latter category including relational, political and religious conflicts (Roberts, 2009; Rockwell, 2007). While financial COIs are more common at medical journals (Blum, Freeman, Dart, \& Cooper, 2009), relational conflicts have been more common at JIBS. Relational COIs include, for example, authors nominating as their recommended editor or reviewers individuals who are recent or current co-authors, colleagues in the same department, supervisor of their dissertation and so on (for more examples, see Rockwell, 2007). The motivation behind such nominations may be similar to "forum shopping", that is, looking for a sympathetic forum (editor and/or reviewer) for the manuscript.

COIs are not, in and of themselves, considered misconduct in research, but they provide opportunities 
for individuals to behave opportunistically. In addition, COIs - whether real, apparent or potential - reduce individuals' confidence in the reliability of professional organizations and their decision-making processes. COIs are particularly pernicious for scholarly journals because they can reduce the confidence that individuals have in research. Rockwell (2007: 6) argues that individuals should assess whether they have a potential COI that (1) would or could compromise their objectivity and judgment; or (2) would or could appear to do so and therefore would either compromise the value of the assessment, or might put their reputation at risk if the conflict were discovered afterwards and questioned. She offers two useful rules of thumb that we would also recommend at JIBS: when in doubt, discuss COIs with the editor, and err on the side of caution. ${ }^{3}$

At JIBS, authors, reviewers and editors are required to disclose and avoid any actual, apparent or perceived COIs during the reviewing process. Regularly, however, I see authors nominating individuals who are not at arm's length from the author to be their editor or reviewer. Three recent examples include: nominating as a reviewer an individual who was a co-author on another manuscript; nominating as an editor one of the author's current co-authors; and nominating as a reviewer someone who was thanked in the acknowledgements for providing comments on the paper. In each of these cases, while I am sure that the nominated individual would have provided an independent and unbiased assessment of the manuscript, the appearance of unbiasedness and independence is lost due to the COI.

\section{Motivations}

One can speculate as to motivations and circumstances that could lead scientists to behave badly. Transaction cost theorists will see this as rational behavior by individuals who are self-interest seeking with guile. In the presence of uncertainty and bounded rationality, authors have incentives to behave opportunistically, using "calculated efforts to mislead, distort, disguise, obfuscate or otherwise confuse" (Williamson, 1985: 47), particularly when the rewards are high. ${ }^{4}$ Opportunistic behavior is not limited to authors, but can also affect reviewers and editors. Miller (2006) provides a useful analysis of the "perils of peer review" that arise from biased judgments, overly harsh critiques or shirking behavior by reviewers. If the probabilities of detection and punishment are low, authors and reviewers can make a rational benefit-cost calculation and behave opportunistically. Should they, in the rare instance, get caught, there is always the claim of "plausible deniability". 5

Moreover, unfamiliarity with publication norms (e.g., in the case of PhD students and junior scholars) and differences in cultural norms across countries are rationales for behaving badly that do not involve self-interest seeking with guile. There are many potential minefields in the publication process that can trip up an unwary or unprepared author, reviewer or editor. Often, issues are not clear cut, and it is possible to make mistakes. ${ }^{6}$ Moreover, while most journals and professional associations now have codes of ethics, as Kacmar (2009) argues, most scholars probably have not carefully studied these ethics codes and are likely to be unaware that their actions may be contravening stated policies. ${ }^{7}$ As an example, senior scholars with junior co-authors may blame their junior co-authors for any ethical violations, using the grounds that the younger scholar did not know the rules. Note, however, that Schminke (2009: 588) in his discussions with 16 journal editors found that "most ethical violations do not appear to be cases of junior scholars not knowing or understanding the rules" nor caused by "junior scholars running ethical yellow lights because of pressures imposed by tenure time lines".

\section{Solutions}

The solution both Schminke (2009) and Kacmar (2009) recommend is "know the code" and "disclose". These recommendations assume that individuals are not simply engaged in self-interest seeking behavior with guile. They may be boundedly reliable for a wide variety of reasons, that is, they do not respect basic ethics rules even in the absence of malevolence (Verbeke \& Greidanus, 2009). In such cases, routines involving continuous education may be the best remedy, both in terms of efforts at disseminating an ethics code and in terms of encouraging disclosure.

In Fall 2009, the JIBS Editors decided to become more actively involved in implementing and enforcing the JIBS Code of Ethics, implementing a multi-pronged strategy for strengthening ethical standards and behaviors at the journal. Perhaps the most important decision was to join the Committee on Publication Ethics, COPE, http://www .publicationethics.org. COPE was founded 12 years ago by a group of medical journal editors concerned about publication misconduct (e.g., plagiarism, 
redundancy, fraudulent data, unethical research, breaches of confidentiality). Many publishers, including Palgrave (our publisher), have signed all of their journals as COPE members. The JIBS Editors have now rewritten our Code of Ethics to link it more closely with the COPE Code of Conduct; an updated Code was posted on the JIBS website in February 2010.

When a problem is identified, JIBS is now following the general ex post structure for handling ethical violations outlined in the COPE templates (see http://publicationethics.org/flowcharts). When the problems involve an author, he/she is informed that JIBS believes an ethical violation has occurred and is presented with the facts (for example, the plagiarized or redundant sections of the paper are highlighted and attached). The focus is on the facts, not the motive or motives behind the actions, and each situation is treated in confidence. Once the author has responded, and the facts have been ascertained, a final editorial decision is made and the file is closed. For a minor violation this might involve simply rewriting part of the paper; for a major violation, the manuscript would normally be rejected from further review at the journal.

We believe ex ante approaches are preferable, however, to the ex post identification of violations and related sanctions. The questions that authors complete when they submit a manuscript to JIBS have been tightened and clarified to ensure that the authors are aware of the ethical norms and practices at JIBS, and are less likely to just "check the box" without reading the statements. Reviewers and editors are also asked to consider and identify any potential COIs before taking on a manuscript. These mechanisms are designed to alert JIBS authors, editors and reviewers to potential code violations, with the hope of discouraging such behaviors ex ante.

Lastly, the JIBS Editors are actively engaged in an ethical-standards diffusion process to inform the JIBS community and wider IB community of scholars as to what we consider best ethical practices for scholarly research. We hope that, through a combination of preventative education and clearly outlined consequences of violations (credible threats), our editorial team can raise the standards of journal ethics at JIBS, with perhaps positive spillover impacts on other scholarly business journals and on the more macro-level functioning of the Academy of International Business itself.
We ask for your active engagement in this process. As Kacmar argues in her 2009 Letter from the Editors in the Academy of Management Journal: "it is equally important for each of us to walk the walk as well as talk the talk when it comes to ethical behavior" if we want to serve as ethical role models for our students and colleagues.

\section{ACKNOWLEDGEMENTS}

An earlier draft of this Letter was circulated to the JIBS Consulting Editor and Editorial Review Boards. I thank Anne Hoekman, the JIBS Editors and the two Boards for helpful comments on the earlier draft.

\section{NOTES}

${ }^{1}$ There are some exceptions to this rule; for example, the author may receive permission in advance to publish the duplicate material elsewhere, such as a JIBS journal article later appearing as a book chapter. See the JIBS Code of Ethics for these exceptions.

${ }^{2}$ It should be mentioned that where an author fully cross-references another of his/her papers, this could enable a reviewer to identify the author, which would violate the JIBS double-blind review process. To comply with double-blind review, JIBS recommends that the author submit two versions of the manuscript to the journal: one for the editors and a second one for the reviewers. The reviewers' copy should have identifying information removed when cross-referencing other manuscripts in the text and bibliography. Information on other relevant papers should also be provided to JIBS at the time of submission. The JIBS Manuscript Central Originality Questions provide space for an author to identify related manuscripts and upload them for review.

${ }^{3}$ For example, to avoid COIs, no AIB Board member can serve as Area or Consulting Editor at JIBS while on the AIB Board; as Editor-in-Chief, I have committed to not publishing in JIBS during my tenure; and manuscripts submitted to JIBS by an Area Editor are not assigned to another Area Editor.

${ }^{4}$ For example, in addition to tenure and promotion motivations, some universities are now paying \$US 5000-10,000 to authors who have a paper accepted for publication in an A-level journal.

${ }^{5} \mathrm{An}$ example of plausible deniability is the following paraphrased response by an author to the discovery by the JIBS Office that most of his/her submission was included in a paper under review elsewhere: I believe that this situation is not a case that the JIBS Code of Ethics was trying to avoid. I now know I should pay extra attention as an author to avoid any problems in 
advance. JIBS might want to recognize that this situation is not a clear violation of the code, as it originally might have looked.

${ }^{6}$ Discussing possible situations and how they might be handled/avoided is a useful way to raise faculty awareness. For example, at the 2009 Academy of Management meetings, all of the participants in the doctoral consortia received some training on publication ethics. An All-Academy Symposium on Publication Ethics is in the planning stages for the 2010 Academy of Management meetings in Montreal.

\section{REFERENCES}

Blum, J. A., Freeman, K., Dart, R. C., \& Cooper, R. J. 2009. Requirements and definitions in conflict of interest policies of medical journals. Journal of the American Medical Association, 302(20): 2230-2234.

Felten, E. 2010. New episodes of scientists behaving badly. Wall Street Journal, 5 February: W11.

Kacmar, K. M. 2009. From the editors: An ethical quiz. Academy of Management Journal, 52(3): 432-434.

Miller, C. C. 2006. Peer review in the organizational and management sciences: Prevalence and effects of reviewer hostility, bias, and dissensus. Academy of Management Journal, 49(3): 425-431.

Responsible Conduct of Research. 2010. Online modules. New York: Office of Research Compliance and Training, Columbia University. http://www.columbia.edu/ccnmtl/projects/rcr/ index.html.

Roberts, J. 2009. An author's guide to publication ethics: A review of emerging standards in biomedical journals.
${ }^{7}$ Some professional associations still lack a code of ethics that outlines good governance practices, proscribes certain behaviors and establishes $\mathrm{COI}$ rules, for example, for selection processes and awards. The Academy of International Business, for example, does not have an ethics code as of February 2010. The Academy of Management, on the other hand, for some years has had a formal Code of Ethics, written policies to handle complaints of ethical violations and an ethics committee. See http://www .aomonline.org.

Headache: The Journal of Head and Face Pain, 49(4): 578-589.

Rockwell, S. 2007. Ethics of peer review: A guide for manuscript reviewers. New Haven, CT: Yale University School of Medicine. http://ori.dhhs.gov/education/products/yale/prethics.pdf.

Schminke, M. 2009. Editor's comments: The better angels of our nature - Ethics and integrity in the publishing process. Academy of Management Review, 34(4): 586-591.

Verbeke, A., \& Greidanus, N. 2009. The end of the opportunism vs trust debate: Bounded reliability as a new envelope concept in research on MNE governance. Journal of International Business Studies, 40(9): 471-495.

Williamson, O. E. 1985. The economic institutions of capitalism. New York: Free Press.

Wilson, J. 2002. Responsible authorship and peer review. Science and Engineering Ethics, 8(2): 155-174. 